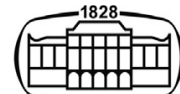

AKADÉMIAI KIADÓ

Acta Chromatographica

34 (2022) 1, 18-23

DOI:

$10.1556 / 1326.2020 .00864$

(c) 2020 The Author(s)

ORIGINAL RESEARCH

PAPER

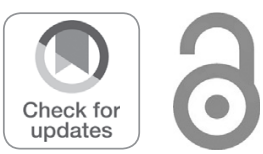

\title{
Development of a rapid UPLC-MS/MS method for the determination of toddalolactone in mouse blood and its application in pharmacokinetics
}

\author{
JING $\mathrm{ZHOU}^{1 \dagger}, \mathrm{HONGZHE} \mathrm{WANG}^{2 \dagger}$, $\mathrm{CAIYUN} \mathrm{MIAO}^{1}$, \\ YUNXI YAO ${ }^{1}$ and JIANSHE $\mathrm{MA}^{2 *}$ (1) \\ ${ }^{1}$ Department of Pharmy, Ningbo Women \& Children Hospital, Ningbo 315032, China \\ ${ }^{2}$ School of Basic Medicine, Wenzhou Medical University, Wenzhou 325035, China
}

Received: October 12, 2020 • Accepted: December 8, 2020

Published online: February 5, 2021

\begin{abstract}
A rapid and simple UPLC-MS/MS method was developed to determine toddalolactone in mouse blood and applied to measure the pharmacokinetics of toddalolactone in mice. Blood samples were first preprocessed by ethyl acetate liquid-liquid extraction. Oxypeucedanin hydrate (internal standard, IS) and toddalolactone were gradient eluted from a UPLC BEH C18 column using a mobile phase consisting of acetonitrile and water ( $0.1 \%$ formic acid). Using electrospray ionization (ESI) as the ionization source, multiple reaction monitoring was used to detect the precursor and product ions of $\mathrm{m} / \mathrm{z} 309.2$ and 205.2, respectively, for toddalolactone and of $m / z 305.1$ and 203.0 for IS, respectively, for quantitative detection. A calibration curve was run over the concentration range of $5-4,000 \mathrm{ng} / \mathrm{mL}(r>$ 0.995). The matrix effects ranged from 93.5 to $98.4 \%$, and the recovery was higher than $77.3 \%$. The precision was less than $13 \%$, and the accuracy ranged from 90.9 to $108.4 \%$. The developed UPLC-MS/ MS method was successfully used for measuring the pharmacokinetics of toddalolactone in mice after oral $(20 \mathrm{mg} / \mathrm{kg})$ and intravenous administration $(5 \mathrm{mg} / \mathrm{kg})$, and the absolute bioavailability of toddalolactone was $22.4 \%$.
\end{abstract}

\section{KEYWORDS}

toddalolactone, mice, UPLC-MS/MS, determination, bioavailability

\section{INTRODUCTION}

The flowering plant species Toddalia asiatica (L.) Lam. has been found to be efficacious in treating hemostasis, removing blood stasis, and relieving pain [1]. As a traditional medicine that is used in the Guizhou, Guangxi, and Yunnan provinces, the plant is widely applied in the treatment of rheumatic arthralgia, stroke injury, and swelling. Toddalolactone, a natural coumarin that is produced by Toddalia asiatica (L.) Lam, has been shown to exhibit antifibrotic and anti-thrombotic effects in vitro and in vivo [2]. Despite its employment to treat a broad range of conditions, little is known about the absorption, distribution, metabolism, and excretion (ADME) properties of toddalolactone. There have been several literatures reported

${ }^{\dagger}$ These authors contributed equal to this work.

*Corresponding author.

E-mail: jianshema@gmail.com for determination $\mathrm{f}$ toddalolactone in Toddalia asiatica (L.) Lam. by HPLC or UPLC-QTOFMS/MS [3-5]. However, until now, there have been no reports on the pharmacokinetic profile of toddalolactone in biological fluids.

Compared to conventional HPLC, UPLC has better separation ability, better chromatographic peak shape, and less interference from matrix effects [6,7]. To better understand the pharmacokinetics, an analytical method for the determination of toddalolactone in biological fluids is necessary. Therefore, it was necessary to first develop a UPLC-MS/MS method for 
identification of toddalolactone in mouse blood and apply these methods toward the determination of toddalolactone pharmacokinetics.

\section{EXPERIMENTAL}

\section{Materials}

Toddalolactone and oxypeucedanin hydrate (IS) (both purity $>98 \%$ ) were obtained from Chengdu Munster biotechnology Co. Ltd (Chengdu, China). HPLC-grade formic acid, acetonitrile, and methanol were obtained from Merck, KGaA (Darmstadt, Germany). Milli-Q water system was purchased from Millipore Sigma (Burlington, MA, USA). Twelve Institute of Cancer Research (ICR) mice (male, 20$22 \mathrm{~g}$ ) were obtained from Laboratory Animal Center of Wenzhou Medical University (Wenzhou, China).

\section{Instrument and condition}

An ACQUITY H-Class UPLC equipped with a XEVO TQSmicro triple quadrupole mass spectrometer (Waters Corp, Milford, MA, USA) with electrospray ionization (ESI) was used for the analysis of the mouse blood samples. A UPLC $\mathrm{BEH} \mathrm{C18}(1.7 \mu \mathrm{m}, 2.1 \times 50 \mathrm{~mm})$ column maintained at 30 ${ }^{\circ} \mathrm{C}$ was used for separation. The mobile phase consisted of acetonitrile and water (w/0.1\% formic acid). The flow rate was set at $0.4 \mathrm{~mL} / \mathrm{min}$. The gradient conditions were as follows: $0-0.2 \mathrm{~min}, 10 \%$ acetonitrile; $0.2-1.4 \mathrm{~min}, 10-85 \%$ acetonitrile; $1.4-2.0 \mathrm{~min}, 85 \%$ acetonitrile; $2.0-2.1 \mathrm{~min}, 85-$ $10 \%$, acetonitrile; $2.1-3.5 \mathrm{~min}, 10 \%$ acetonitrile.

The mass condition was set as follows: dry gas (nitrogen) flow rate of $900 \mathrm{~L} / \mathrm{h}$, capillary voltage of $2 \mathrm{kV}$, the temperature of source ionization of $150{ }^{\circ} \mathrm{C}$, the temperature for drying gas of $450{ }^{\circ} \mathrm{C}$. Quantitative analysis of the blood samples was operated in ESI positive mode with multiple reaction monitoring $(\mathrm{MRM}), \mathrm{m} / z 309.2 \rightarrow 205.2$ for toddalolactone (cone voltage $20 \mathrm{v}$, collision voltage $24 \mathrm{v}$ ) and $\mathrm{m} / z 305.1 \rightarrow 203.0$ for IS (cone voltage $34 \mathrm{v}$, collision voltage $10 \mathrm{v})$, Fig. 1.

\section{Calibration standards}

Stored solutions of toddalolactone $(1.0 \mathrm{mg} / \mathrm{mL})$ and oxypeucedanin hydrate $(1.0 \mathrm{mg} / \mathrm{mL})$ were prepared in a $1: 1$ $(\mathrm{v} / \mathrm{v})$ solution of methanol and water. Working standard solutions were diluted from the stock solution of toddalolactone with methanol to final concentrations of 50, 200, $500,2000,5,000,10,000,20,000$ and $40,000 \mathrm{ng} / \mathrm{mL}$. The stored stock solution of oxypeucedanin hydrate was diluted with methanol to obtain a working standard solution with a final concentration of $100 \mathrm{ng} / \mathrm{mL}$.

Blank mouse blood was spiked with toddalolactone to generate calibration standards with toddalolactone concentrations of 5, 20, 50, 200, 500, 1,000, 2,000, and 4,000 ng/mL. Three quality control (QC) samples, with concentrations of 10,450 , and $3,600 \mathrm{ng} / \mathrm{mL}$, were also prepared in the same manner as the calibration standards. All samples were stored at $-20{ }^{\circ} \mathrm{C}$.
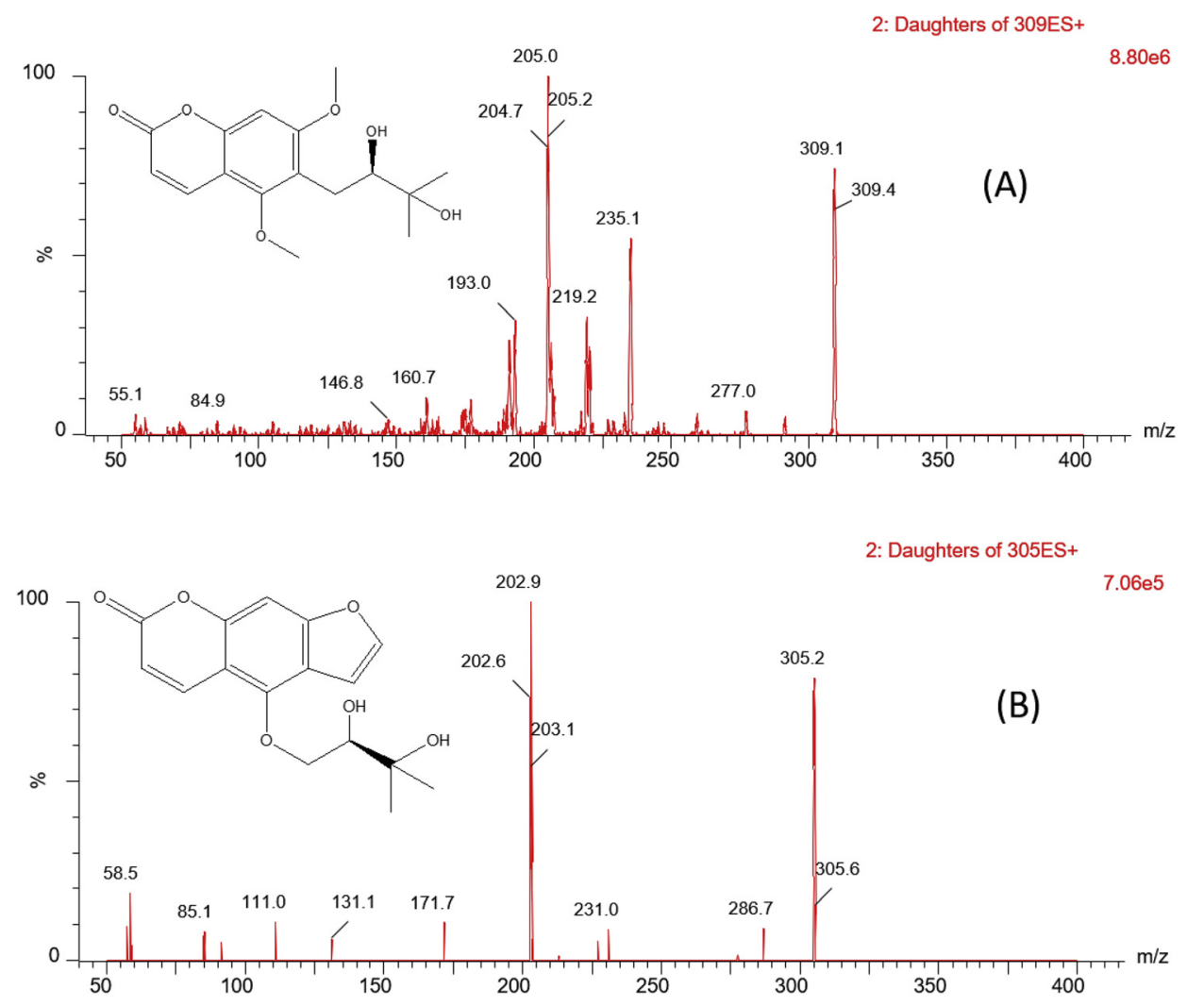

Fig. 1. Chemical structure and mass spectra of toddalolactone (A) and oxypeucedanin hydrate (IS, B) 


\section{Sample preparation}

The blood sample $(20 \mu \mathrm{L})$ was added to a $1.5 \mathrm{~mL}$ centrifugation tube, and $10 \mu \mathrm{L}$ of the internal standard solution (100 $\mathrm{ng} / \mathrm{mL}$ ) was added, followed by $1 \mathrm{~mL}$ of ethyl acetate. The tube containing the sample was vortexed for $1.0 \mathrm{~min}$ and then centrifuged at $3,000 \mathrm{rpm}$ for $10 \mathrm{~min}$ at $4{ }^{\circ} \mathrm{C}$; the supernatant $(0.9 \mathrm{~mL})$ was then dried under a stream of air and reconstituted in $50 \mu \mathrm{L}$ of methanol. After centrifugation, the supernatant $(2 \mu \mathrm{L})$ was injected into the UPLC-MS/MS for analysis.

\section{Method validation}

The UPLC-MS/MS method validation was performed according to the US Food and Drug Administration (FDA) bioanalytical guidelines [8].

Selectivity. The selectivity of the UPLC-MS/MS method was evaluated by analyzing blank mouse blood, the blank mouse blood spiked with toddalolactone and the IS, and a mouse sample.

Calibration of the Standards. A calibration curve was generated using the standards over the concentration range of 5-4,000 ng/mL. Each peak was integrated to determine the peak area, and the peak areas were plotted against the known concentration of the standards to generate a standard curve that was evaluated for its linearity. The lower limit of quantification (LLOQ) was defined as the lowest concentration on the calibration curves. The precision at LLOQ should be less than $20 \%$, and accuracy should be between 80 and $120 \%$. The limit of detection (LOD), defined as a signal/ noise ratio of 3 .

Precision and accuracy. The precision and accuracy were evaluated by measuring mouse blood QC samples at in six replicates. Expressed as relative standard deviation (RSD), the precision on the same day (intra-day) and on different days (inter-day) was determined by measuring the QC samples for three consecutive days. The accuracies of these QC samples on the same day and on different days were measured based on the average value of the QC samples and the true value for three consecutive days.

Recovery and matrix effects. The recovery was evaluated by comparing the measured peak area of the QC samples with the corresponding standard peak area. The matrix effect was evaluated by comparing the peak area of the blank mouse blood with the standard solution after sample treatment and the peak area of the corresponding standard solution.

Stability. The stability of toddalolactone in mouse blood was investigated by analyzing the QC samples placed under three different storage conditions: $-20{ }^{\circ} \mathrm{C}$ for 30 days (longterm stability), $2 \mathrm{~h}$ at room temperature (short-term stability), and 3 consecutive freeze-thawing cycles $\left(-20^{\circ} \mathrm{C}\right.$ to room temperature) for 3 days (freeze-thaw stability).

\section{Pharmacokinetics}

Twelve mice were randomly divided into two groups $(n=$ $6)$. One group was given toddalolactone $(20 \mathrm{mg} / \mathrm{kg})$ by oral administration and another group was given toddalolactone (5 $\mathrm{mg} / \mathrm{kg}$ ) by intravenous administration. This study was approved by the Animal Care Committee of Wenzhou Medical University. The blood samples $(20 \mu \mathrm{L})$ were withdrawn from the caudal vein after dosing at $0.167,0.5,1,1.5$, $2,3,4,6,8 \mathrm{~h}$ and stored at $-20{ }^{\circ} \mathrm{C}$ until analysis. The data obtained from UPLC-MS/MS was fitted by the DSA 2.0 (China Pharmaceutical University, China). The bioavailability was calculated using the following equation: bioavailability $(\%)=100 \% \times \mathrm{AUC}_{\mathrm{po}} \times \mathrm{D}_{\mathrm{iv}} /\left(\mathrm{AUC}_{\mathrm{iv}} \times\right.$ $\mathrm{D}_{\mathrm{po}}$ ), where po refers to oral administration, iv refers to intravenous administration.

\section{RESULTS}

\section{Method validation}

The UPLC-MS/MS chromatograms of a blank blood sample, a blank blood sample spiked with toddalolactone and IS, and a blood sample obtained after oral administration are provided in Fig. 2. No interference was found at the retention times of the toddalolactone and the IS. The calibration curve for the standards that were created over the concentration range of $5-4,000 \mathrm{ng} / \mathrm{mL}$ toddalolactone yielded the linear regression equation $y=0.000355 x+0.000306(r=0.9992$, $n=6$ ), where y represents the ratio of the peak area of toddalolactone to that of IS, and $x$ is the concentration of toddalolactone. The LLOQ was $5 \mathrm{ng} / \mathrm{mL}$. The precision and accuracy of the LLOQ were 12.5 and $90.9 \%$, respectively. The LOD of toddalolactone in mouse blood was $2 \mathrm{ng} / \mathrm{mL}$. The accuracy of the QC samples ranged from 90.9 to $108.4 \%$, the intra-day and inter-day precision was less than $13 \%$, and the matrix effect was between 93.5 and $98.4 \%$, in Table 1 . The stability of toddalolactone in the various condition (room temperature for $2 \mathrm{~h},-20{ }^{\circ} \mathrm{C}$ for 30 days, and 3 freezing and thawing cycles) was acceptable, with the accuracy being between 86 and $115 \%$ and precision being less than $13 \%$.

\section{Pharmacokinetic study}

The main pharmacokinetic parameters of toddalolactone were fitted by the non-compartment model (Table 2). The mean plasma concentration-time profile of toddalolactone after oral administration $(20 \mathrm{mg} / \mathrm{kg})$ and intravenous administration $(5 \mathrm{mg} / \mathrm{kg}$ ) is shown in Fig. 3. The bioavailability of toddalolactone was $22.4 \%$, which represents a good oral absorption.

\section{DISCUSSION}

To better understand the pharmacokinetics of toddalolactone, mass spectrometry conditions were optimized. The 

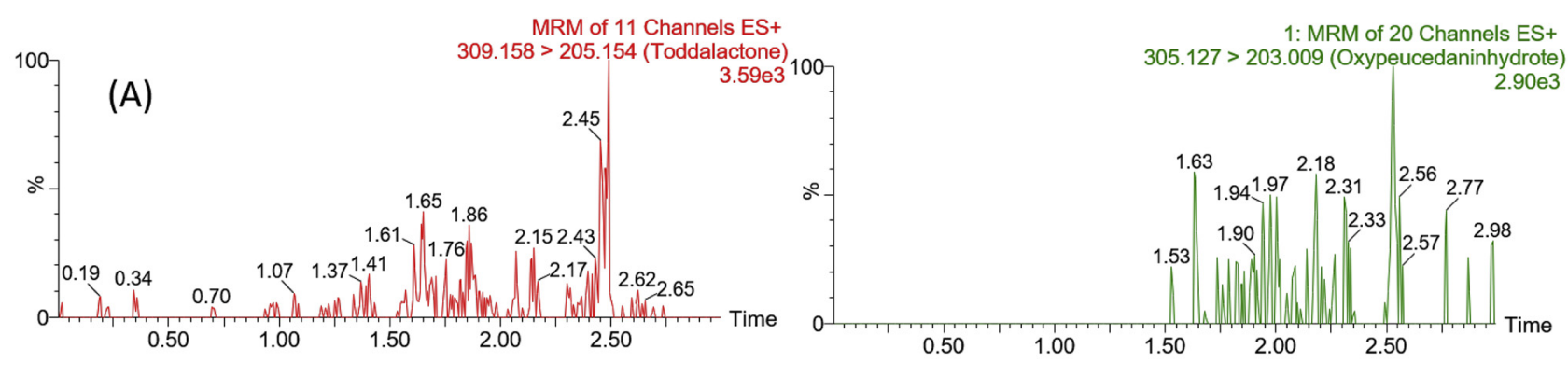

MRM of 11 Channels ES+
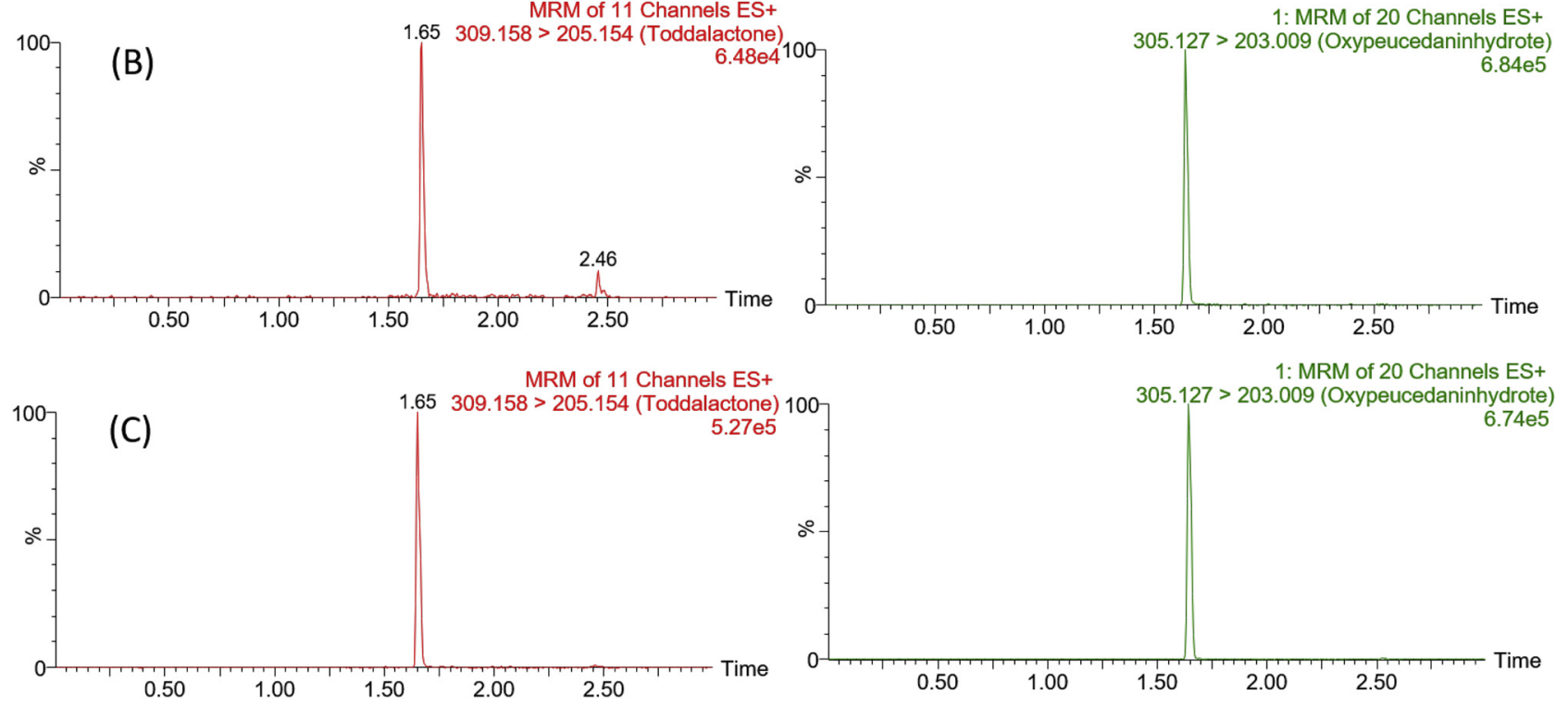

Fig. 2. Toddalolactone and IS chromatograms obtained by UPLC/MS/MS in mouse blood (A) a blank blood sample, (B) the blank blood samples spiked with toddalolactone $(5 \mathrm{ng} / \mathrm{mL})$ and IS, (C) a blood samples after oral administration

Table 1. The accuracy, precision, matrix effect, and recovery of toddalolactone in mouse blood samples $(n=6)$

\begin{tabular}{lcccccccc}
\hline & \multicolumn{2}{c}{ Accuracy (\%) } & & \multicolumn{2}{c}{ Precision (RSD\%) } & & \\
\cline { 2 - 3 } Concentration $(\mathrm{ng} / \mathrm{mL})$ & Intra-day & Inter-day & & Intra-day & Inter-day & & Matrix effect & Recovery \\
\hline 5 & 97.8 & 90.9 & & 10.4 & 12.5 & 95.6 & 90.7 \\
10 & 103.4 & 108.4 & & 9.1 & 10.4 & 93.5 & 77.3 \\
450 & 104.1 & 107.8 & & 1.4 & 3.4 & 97.9 & 85.0 \\
3,600 & 100.0 & 101.4 & & 5.2 & 5.3 & & 98.4 & 83.0 \\
\hline
\end{tabular}

Table 2. Pharmacokinetic analysis of toddalolactone after oral and intravenous administration

\begin{tabular}{|c|c|c|c|}
\hline Parameters & $\mathrm{U}_{\mathrm{int}}$ & po $(20 \mathrm{mg} / \mathrm{kg})$ & iv $(5 \mathrm{mg} / \mathrm{kg})$ \\
\hline $\mathrm{AUC}_{(0-\mathrm{t})}$ & $\mathrm{ng} / \mathrm{mL}^{*} \mathrm{~h}$ & $2725.6 \pm 754.3$ & $3041.6 \pm 327.0$ \\
\hline $\operatorname{AUC}_{(0-\infty)}$ & $\mathrm{ng} / \mathrm{mL}{ }^{*} \mathrm{~h}$ & $2735.0 \pm 751.0$ & $3042.8 \pm 326.0$ \\
\hline $\operatorname{MRT}_{(0-t)}$ & $\mathrm{H}$ & $0.9 \pm 0.2$ & 0.8 \\
\hline $\operatorname{MRT}_{(0-\infty)}$ & $\mathrm{H}$ & $0.9 \pm 0.2$ & $0.8 \pm 0.1$ \\
\hline$t_{1 / 2 z}$ & $\mathrm{~h}$ & $1.3 \pm 1.0$ & $0.8 \pm 0.6$ \\
\hline $\mathrm{T}_{\max }$ & $\mathrm{h}$ & $0.5 \pm 0.3$ & 0.2 \\
\hline $\mathrm{CL}_{\mathrm{z} / \mathrm{F}}$ & $\mathrm{L} / \mathrm{h} / \mathrm{kg}$ & $14.3 \pm 15.4$ & $1.8 \pm 1.7$ \\
\hline $\mathrm{V}_{\mathrm{z} / \mathrm{F}}$ & $\mathrm{L} / \mathrm{kg}$ & $7.8 \pm 2.2$ & $1.7 \pm 0.2$ \\
\hline $\mathrm{C}_{\max }$ & $\mathrm{ng} / \mathrm{mL}$ & $2595.5 \pm 499.9$ & $2892.8 \pm 544.0$ \\
\hline Bioavailability & & $22.4 \%$ & \\
\hline
\end{tabular}

positive-ion mode provided a stronger response for the detection of toddalolactone than the negative-ion mode. Fragment peaks with relatively high signal intensity were selected as quantitative ion pairs, with $\mathrm{m} / z 309.2 \rightarrow 205.2$ for toddalolactone (cone voltage $20 \mathrm{v}$, collision voltage $24 \mathrm{v}$ ) and $\mathrm{m} / z 305.1 \rightarrow 203.0$ for IS (cone voltage $34 \mathrm{v}$, collision voltage $10 \mathrm{v}$ ), were shown in Fig. 1.

Various mobile phases were tested, such as acetonitrile and $0.1 \%$ formic acid in water, acetonitrile and water, acetonitrile with $10 \mathrm{mmol} / \mathrm{L}$ ammonium acetate, methanol with $0.1 \%$ formic acid in water, methanol and water, and methanol with $10 \mathrm{mmol} / \mathrm{L}$ ammonium acetate. Based on the elution profiles in each of these mobile phases, acetonitrile 


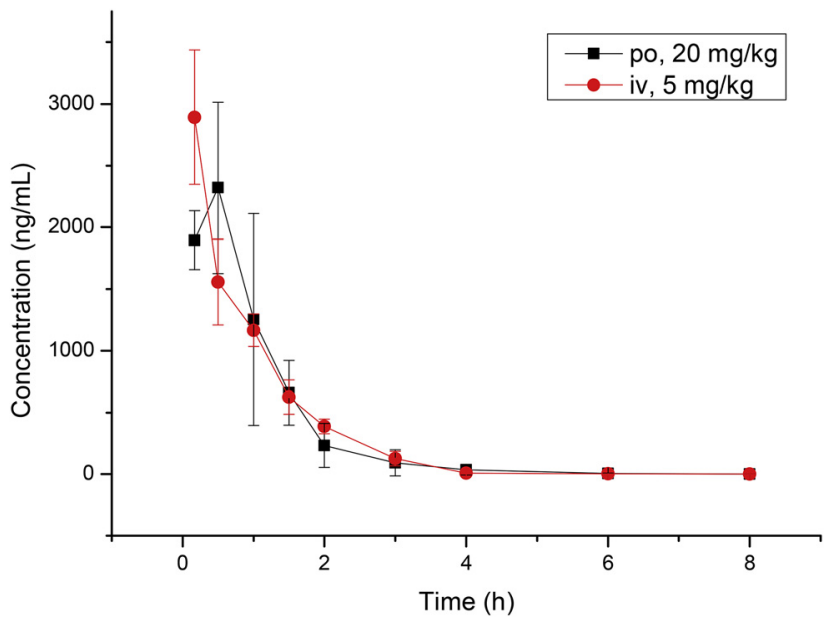

Fig. 3. Mean plasma concentration-time profile after oral administration $(20 \mathrm{mg} / \mathrm{kg})$ and intravenous administration of toddalolactone $(5 \mathrm{mg} / \mathrm{kg})$

with $0.1 \%$ formic acid in water was determined to be the best mobile phase because it achieved a better peak with suitable retention time. A UPLC BEH C18 column (Waters) was chosen for chromatography because it provided a better peak shape than other columns tested.

Choosing suitable sample treatment method was an important step in the methodology [9-12]. The extraction efficiencies of acetonitrile, ethyl acetate, and methanol were compared. The extraction efficiencies of ethyl acetate and acetonitrile (around 80\%) were similar, which were better than methanol (around 70\%). However, the blood sample extraction by acetonitrile had poor matrix effects (around $75 \%$ ), and the matrix effect from ethyl acetate was better (around 95\%). Taking ethyl acetate as the extraction solvent into consideration, the method validation showed that using ethyl acetate for liquid-liquid extraction could obtain satisfactory sensitivity and extraction efficiency. Compared to a rat, the blood volume of a mouse is relatively unsuitable for withdrawing a significant amount of blood, but this experiment only requires $20 \mu \mathrm{L}$ of blood for pharmacokinetics analysis. However, the small volume of blood withdrawn is not adequate enough for centrifugation to separate the blood for serum analysis. In this study, the accuracy, precision, matrix effect, and stability of the direct liquid-liquid extraction of blood met the requirements of biological testing, which allowed direct use of the blood samples for detection and analysis.

It was also an important task to select the best internal standard during the method development [13-17]. In this experiment, several compounds including diazepam, carbamazepine, oxypeucedanin hydrate, bupivacaine, and lidocaine were compared. Of all the internal standards tested, oxypeucedanin hydrate demonstrated the best peak shape, has a more stable chemical structure, and the peak time was similar to that of toddalolactone, all of which were necessary for correct function of the internal standard in the experiments.
UPLC-MS/MS was utilized in the quantitative analysis of toddalolactone in mouse blood because it was much faster than traditional HPLC. Toddalolactone was eliminated from blood with a $\mathrm{t}_{1 / 2}$ of $1.3 \pm 1.0$ and $0.8 \pm 0.6 \mathrm{~h}$ for intravenous and oral administration, respectively. These results indicated that blood plasma metabolism was fast in mice. The $\mathrm{AUC}_{(0-\mathrm{t})}$ of were $3041.6 \pm 327.0$ and $2725.6 \pm 754.3 \mathrm{ng} / \mathrm{mL}^{\star} \mathrm{h}$ for intravenous and oral administration, respectively, which indicated a good oral absorption. The pharmacokinetics of toddalolactone in vivo could help better understand the metabolism of the drug in the body.

\section{CONCLUSIONS}

A simple UPLC-MS/MS method was developed for determination of toddalolactone in mice, with an LLOQ of $5 \mathrm{ng} /$ $\mathrm{mL}$ and a sample running time of only $3.5 \mathrm{~min}$. The method established in this study only required $20 \mu \mathrm{L}$ of blood, which is ideal for biological samples with a limited amount of sample available for testing. In addition, the ethyl acetate liquid-liquid extraction, matrix effect, and recovery all met the requirements. The UPLC-MS/MS method developed was then successfully applied to determine the pharmacokinetics of toddalolactone in mice, which had a bioavailability of $22.4 \%$. Toddalolactone was eliminated from blood with a $t_{1 / 2}$ of $1.3 \pm 1.0$ and $0.8 \pm 0.6 \mathrm{~h}$ for intravenous and oral administration, respectively. The pharmacokinetics of toddalolactone in vivo was reported for the first time, it help better understand the metabolism of the toddalolactone in vivo.

\section{ACKNOWLEDGMENTS}

This study was supported the Ningbo Natural Science Foundation (2019A610286).

\section{REFERENCE}

1. Yu, B.; Zhang, G.; Jin, L.; Zhang, B.; Yan, D.; Yang, H.; Ye, Z.; Ma, T. Front. Pharmacol. 2017, 8, 489.

2. Ni, J.; Zhao, Y.; Su, J.; Liu, Z.; Fang, S.; Li, L.; Deng, J.; Fan, G. Front. Pharmacol. 2020, 11, 109.

3. Zhu, M.; Wei, P.; Peng, Q.; Qin, S.; Zhou, Y.; Zhang, R.; Zhu, C.; Zhang, L. Phytochem. Anal. 2019, 30, 164-81.

4. Cao, C.; Du, P.; Zhu, X.; Yan, H.; Song, X.; Zhu, H.; Geng, Y.; Wang, D. J. Sep. Sci. 2019, 42, 2621-7.

5. Ran, Y. H.; Zhou, Q.; Zhou, Y.; Yang, S. L. Chin. Pharm. J. 2014, 49, 240-3.

6. Nahar, L.; Onder, A.; Sarker, S. D. Phytochem. Anal. 2020, 31, 413-57.

7. Medvedev, Y. V.; Ramenskaya, G. V.; Shokhin, I. E.; Yarushok, T. A. Pharm. Chem. J. 2013, 47, 225-30.

8. US Department of Health and Human Services, F.a.D.A. Guidance for Industry: Bioanalytical Method Validation, 2013.

9. Xie, H. L.; Lu, X. J.; Jin, W. Q.; Zhou, H.; Chen, D. X.; Wang, X. Q.; Zhou, Y. F. Curr. Pharm. Anal. 2020, 16, 438-45. 
10. Lin, G. T.; Chen, Y. Y.; Yu, Y.; Wang, H. Z.; Wang, X. Q.; Chen, L. M. Latin Am. J. Pharm. 2020, 39, 1105-9.

11. Chen, L. G.; Weng, Q. H.; Lin, Y. J.; Lu, X. J.; Zhong, Z. Q.; Xiong, J. H.; WangX.Q. Curr. Pharm. Anal. 2020, 16, 705-11.

12. Ye, W.J.; Lin, C. L.; Lin, G. Y.; Chen, R. J.; Sun, W.; Wang, S. H.; Wang, X. Q.; Zhou, Y. F. Curr. Pharm. Anal. 2019, 15, 604-11.

13. Li, T. R.; Ye, W. J.; Huang, B. G.; Lu, X. J.; Chen, X. X.; Lin, Y. J.; Wen, C. C.; Wang, X. Q. J. Pharm. Biomed. Anal. 2019, 168, 133-7.
14. Weng, Q. H.; Weng, T. T.; Lin, Y. J.; Lu, X. J.; Zhong, Z. Q.; Chen, L. G.; XiongJ. H.; Wang, X. Q. Latin Am. J. Pharm. 2019, 38, 431-6.

15. Song, H. C.; Huang, Y.W.; Zhu, D.Q.; Tong, S. H.; Zhang, M. L.; Wang, X. Q.; Bao, X. Curr. Pharm. Anal. 2019, 15, 194-9.

16. Wei, Z.; Ye, L. X.; Jiang, Y. Y.; Zhang, Z. G.; Wang, X. Q. Latin Am. J. Pharm. 2018, 37, 523-8.

17. Wang, H. Y.; Chen, Y. C.; Wan, J. F.; Xu, J. L.; Mo, J. J.; Qian, S. Y.; Zhou, Y. F.; Wang, X. Q.; Huang, G. Latin Am. J. Pharm. 2018, 37, 1724-9.

Open Access. This is an open-access article distributed under the terms of the Creative Commons Attribution-NonCommercial 4.0 International License (https:// creativecommons.org/licenses/by-nc/4.0/), which permits unrestricted use, distribution, and reproduction in any medium for non-commercial purposes, provided the original author and source are credited, a link to the CC License is provided, and changes - if any - are indicated. 